\title{
JUVENTUDE COMO PROBLEMA DE POLÍTICAS PÚBLICAS
}

\author{
Marcia Frezza, Cleci Maraschin e Nair Silveira dos Santos \\ Universidade Federal do Rio Grande do Sul, Porto Alegre, Brasil
}

RESUMO: Tendo como foco discutir concepções de juventudes que se expressam em políticas públicas para jovens no Brasil, concentramos nossa pesquisa no Consórcio Social da Juventude. A partir da perspectiva da Psicologia Social, usamos como estratégia metodológica a problematização e como ferramenta teórica conceitos de Michel Foucault. Buscamos compreender como as práticas discursivas instituídas em políticas públicas definem e denominam parcelas da juventude. Ao problematizarmos as tensões elencadas do material analisado, discutimos quatro concepções de juventude: voluntária, digitalizada, trabalhadora e vulnerabilizada. Estas se constituíram em profícuos indicadores de análise para a problematização dos enunciados dos documentos e entrevistas. A análise sinalizou o quanto as políticas públicas de juventude estão inseridas em uma rede discursiva que desenha, forma e institui modos de viver de jovens - de baixa renda - na contemporaneidade. Observamos que, de forma generalizada, discursos de educação, cidadania, inclusão, entre outros, operam, principalmente, para legitimar programas de políticas públicas.

PALAVRAS-CHAVE: juventude; políticas públicas; vulnerabilidade; inclusão digital; trabalho.

\section{YOUTH AS A PROBLEM OF GOVERNMENT POLICIES}

ABSTRACT: Focusing on concepts of youth expressed in government policies for young people in Brazil, we concentrated our research in the Consórcio Social da Juventude - a national project developed by the Brazilian Government. From the Social Psychology perspective, we used the problematization as a methodological strategy and concepts of Michel Foucault as theoretical tools. We sought to comprehend how the discoursive practices installed in government policies define and establish portions of young people. Problematizing the tensions verified in the material analysed, we discussed four concepts of young people: volunteer, digitalized, worker and vulnerabilized. They turned into proficuous indicators of analysis for the proposed problematization. The analysis suggests how government policies are inserted in a discoursive net that designs and constitutes ways of living of young people - especially those of low income. We observed that discourses of education, citizenship, inclusion, among others, operate to offer credibility to programmes of government policies for young people.

KEYWORDS: young people; government policies; vulnerability; digital inclusion; work.

Este artigo analisa parte dos dados levantados para fins da elaboração de uma dissertação de mestrado em Psicologia Social que teve como foco questões relacionadas a parcelas da juventude que participam de projetos de políticas públicas. Destacamos a importância de analisar como os jovens vêm se constituindo objeto de investimento e intervenção dentro do território das políticas públicas de juventude. A partir do lugar da Psicologia Social, usando como estratégia metodológica a problematização e como ferramenta teórica conceitos de Michel Foucault, tomamos para análise experiências do Consórcio Social da Juventude (CSJ) em Porto Alegre, RS, no período compreendido entre 2005 e 2006. O CSJ foi um projeto criado a partir do Programa Nacional de Estímulo ao Primeiro Emprego para os Jovens (PNPE), desenvolvido pelo Governo
Federal, através do Ministério do Trabalho e Emprego. Esse projeto previa a parceria da sociedade civil organizada (instituições de ensino, órgãos públicos, empresas, entidades sociais e órgãos de representação dos trabalhadores) para a elaboração e execução das atividades desenvolvidas.

Optamos pelo CSJ porque buscávamos um projeto de caráter nacional que tivesse uma orientação descentralizadora e que previsse a parceria de entidades sociais. Outra razão importante foi o fato de o CSJ ter, dentre os objetivos e as atividades desenvolvidas - conforme documentos avaliados pela presente pesquisa - , questões referentes ao trabalho e à educação que circunscrevem o universo de uma parcela da juventude brasileira.

$\mathrm{Na}$ fase inicial da pesquisa, o CSJ estava em sua segunda edição, com perspectivas promissoras de 
continuidade para os anos seguintes, contando com a participação de diferentes entidades. Isso proporcionou um conjunto muito rico de dados, dos quais tivemos que eleger apenas parte, em função dos limites delineados pelo artigo. Utilizamos, para a análise, documentos de políticas públicas no âmbito nacional (Manual de Implementação Junto às Entidades Sociais, 2005 e o Plano Nacional de Juventude) e, no âmbito regional, planos de trabalho de algumas entidades locais, referentes às ações desenvolvidas em Porto Alegre. Além dos documentos, consideramos entrevistas realizadas com agentes de diferentes instituições que participaram do projeto. Dessa forma, buscamos problematizar o conjunto de elementos, no CSJ, que deram condição para a emergência de determinadas concepções de juventude. Também tivemos como propósito dar visibilidade a possíveis tensões presentes no processo de elaboração e desenvolvimento do projeto em foco.

Segundo Foucault (1971/1999), mesmo que todos tenhamos um lugar no discurso, as circunstâncias determinam que não é qualquer um que pode falar sobre qualquer coisa em qualquer lugar. Ao tratar dessas circunstâncias, o autor descreve as interdições do discurso, salientando a estreita ligação entre discurso e poder. Foucault (1982/1995) destaca que o poder se constitui em ato, como "ação sobre ação". Para o autor, as relações de poder são modos de ação que não agem diretamente sobre as pessoas; elas agem sobre a própria ação. Dessa forma, o lugar que ocupamos na ordem do discurso, além de regular o que falamos, regula os efeitos daquilo que falamos e exercemos. Portanto, dependendo do lugar de onde se fala, o que é dito sobre juventude possui determinada legitimidade e ocasiona, do mesmo modo, diferentes efeitos, seja, por exemplo, a partir do discurso médico, seja do jurídico, do psicológico, do educacional ou das políticas públicas.

Por vezes, a juventude é definida por sua característica revolucionária, de potência positiva e transformadora. Em outras circunstâncias, a juventude é identificada como geradora de problemas para a sociedade e como um modo de vida que exige cuidados específicos. Pontuamos, assim, a condição paradoxal posta aos jovens: por vezes considerados em sua potencialidade e, em outras, como vítimas de processos de exclusão ou como população de risco ou em risco (CEPAL-OIJ, 2000, citado por Organização das Nações Unidas para a Educação, a Ciência e a Cultura [UNESCO], 2004).

Não nos interessa aqui assumir uma dessas posições, muitas vezes contraditórias, especialmente porque parecem conferir à juventude uma determinada natureza ou essência - de um lado, potência e, de outro, problema. Sendo assim, não acreditamos ser possível definir uma natureza que seria própria da juventude. Para Foucault (1984), as práticas é que constituem jogos de verdades, ou seja, constituem o conjunto de procedimentos e regras que determinam o que é considerado legítimo ou não em um determinado campo de práticas. Os jogos de verdades produzem regimes de verdades que adquirem legitimidade social, inaugurando, assim, uma verdade. Ao nos darmos conta de que existem regimes de verdade e que, por essa razão, a verdade não é dada a priori e nem é da ordem do natural, percebemos a importância da problematização. Segundo Foucault:

Problematização não quer dizer representação de um objeto preexistente, nem criação pelo discurso de um objeto que não existe. É o conjunto de práticas discursivas ou não discursivas que faz alguma coisa entrar no jogo do verdadeiro e do falso e a constitui como objeto para o pensamento (seja sob a forma de reflexão moral, do conhecimento científico, da análise política etc.) $(1984$, p. 76$)$.

Entendemos que o ato de problematizar inclui a ação de romper com o instituído, possibilitando um certo estranhamento, criando estratégias que permitem dar visibilidade a outras e diferentes formas de pensar, agir e sentir. Por essa razão, a problematização pode ser entendida como elemento indispensável em estratégias de produção de conhecimento.

Buscamos, assim, problematizar as práticas discursivas visibilizadas no projeto investigado práticas que circunscrevem parcelas da juventude que são caracterizadas como problema de políticas públicas, analisando como essas políticas contribuem para a construção de concepções de parcelas da juventude. No sentido de encontrar possíveis tensões do projeto, aprofundamos o exercício do pensamento, tendo como material para a análise um conjunto de documentos do CSJ e relatos de gestores de entidades que participaram do projeto.

\section{Políticas públicas de juventude no Brasil}

Para o início da análise do material mencionado, cabe fazermos uma breve pontuação de algumas questões em relação aos programas de políticas públicas de juventude implementados no Brasil. Nos últimos anos, em nosso país, tem havido maior investimento em programas de políticas públicas de juventude (Lima \& Minayo-Gomez, 2003; Sposito \& Carrano, 2003; Sposito \& Corrochano, 2005; Sposito, Silva, \& Souza, 2006; Tommasi, 2004; UNESCO, 2004). Esses programas visam instituir projetos que, de forma geral, objetivam resolver problemas enfrentados por parcelas da população jovem em sua inserção na ordem social vigente - como aqueles relacionados ao acesso à edu- 
cação, à saúde e ao trabalho; ou referentes a situações caracterizadas como em conflito com a lei. São programas variados em seus enfoques, estratégias, objetivos e modelos. Mas, de modo geral, podemos perceber uma concentração em seu direcionamento: tomam como foco a parcela da juventude qualificada como estando em situação de maior vulnerabilidade social.

Estudos recentes sobre ações decorrentes das políticas públicas para jovens no Brasil evidenciam as diferentes práticas desenvolvidas, assim como questões problemáticas (Castro \& Abramovay, 2002; Lima \& Minayo-Gomez, 2003; Sposito \& Carrano, 2003; Sposito \& Corrochano, 2005; Sposito et al., 2006; Tommasi, 2004). Segundo esses estudos, há uma grande diversidade de iniciativas, descontinuidades e contradições na execução de projetos em diferentes contextos. Uma, dentre as muitas limitações na organização dos programas, destacada pela UNESCO (2004), é a forma desarticulada com que são planejados e implementados, não apresentando uma visão geral e perdendo, assim, a dimensão de conjunto. Com muita frequência, os programas são setorizados em focos específicos, como educação, emprego, saúde, atividades culturais, atividades esportivo-recreativas e outros (UNESCO, 2004). Uma possível ponderação está relacionada ao fato de que a setorização das iniciativas possa comprometer os resultados das mesmas, reduzindo o seu campo de ação.

Outro aspecto observado pela UNESCO (2004) é a centralização da gestão de políticas públicas no nível federal. Esse direcionamento pode dificultar a consideração da experiência, das limitações, das potencialidades e do conhecimento das instituições locais que trabalham com jovens - o que pode minimizar a complexidade dos problemas e reduzir a potencialidade para a superação dos mesmos. Por outro lado, destacamos que iniciativas mais recentes, no campo das políticas públicas, apresentam tendências mais descentralizadoras (UNESCO, 2004) — orientação prevista para o CSJ, uma vez que fomentou integrar entidades locais, que já realizavam projetos sociais na comunidade, na elaboração e desenvolvimento das ações.

Por último, a UNESCO (2004) constata que os jovens que mais se beneficiam com os programas de políticas públicas são aqueles mais integrados socialmente, não atingindo, ou atingindo de forma pouco expressiva, aqueles cujas necessidades são, possivelmente, maiores. Verificamos esse fato na fala de um dos coordenadores de uma das entidades executoras que integrou o CSJ, quando ele nos explicou o modo como os jovens foram selecionados para participar das atividades desenvolvidas pela instituição de que fazia parte. Para a primeira edição, os jovens que tiveram acesso ao projeto já tinham uma relação estreita com a entidade: ou participavam de outros projetos desta entidade ou eram filhos de integrantes da mesma. Para o segundo módulo, os jovens que foram selecionados faziam parte da lista do programa Fome Zero².

Nos dois momentos relatados, constatamos que os jovens participantes já faziam parte de uma rede de amparo social, mesmo que limitada. Uma declaração feita por uma gestora de outra entidade executora corrobora esta análise. Conforme observado por ela, o CSJ tinha como um de seus objetivos o incentivo à educação continuada dos jovens. Dessa forma, para participar do projeto, o jovem deveria apresentar atestados de frequência escolar. Segundo a reflexão da entrevistada, aí residiria uma contradição, uma vez que jovens fora da escola estariam impossibilitados de se beneficiar do projeto. No período aqui considerado (2005-2006), começava em Porto Alegre a experiência de outro programa nacional, o ProJovem (Programa Nacional de Inclusão de Jovens), direcionado a uma parcela dos jovens que não concluíram o ensino fundamental. No final de 2007, o Governo Federal unificou vários projetos voltados para a juventude, integrando-os ao ProJovem, inclusive o CSJ. Em que pesem os esforços empreendidos, podemos perceber as dificuldades que jovens mais distantes das redes de amparo social têm para serem contemplados pelos programas e projetos de políticas públicas.

Um estudo realizado no período entre 2001 e 2004 (Sposito et al., 2006) constatou que os focos principais mais frequentes definidos pelos programas e projetos são esporte, cultura e inserção social. Apesar de as questões relativas ao trabalho juvenil não estarem entre as modalidades principais de atividades mais frequentes, questões sobre a inserção dos jovens no mundo do trabalho compõem o grupo dos cinco objetivos mais citados e previstos nesses programas e projetos. Esse estudo também observou que o mesmo ocorre com o tema da participação ou protagonismo juvenil. Isso significaria que programas focados em determinadas modalidades (esporte, cultura ou inserção social) estariam se propondo a cumprir diferentes metas (participação e trabalho juvenil) que não estariam necessariamente vinculadas às suas áreas específicas (Sposito et al., 2006). Essa tendência revela um aumento da importância que esses dois focos, a participação juvenil e a inserção dos jovens no mundo do trabalho, têm assumido nos programas de políticas públicas de juventude.

A caracterização dos jovens que são beneficiados pelos programas e projetos de políticas públicas prioriza diferentes critérios, tais como: a situação econômica e social; o acesso ou não a bens culturais, sociais e educacionais; a faixa etária; uma possível situação de 
conflito com a lei; dificuldades de inserção no mundo do trabalho. Baseados em tais critérios, os projetos e programas parecem tentar englobar os jovens ditos em vulnerabilidade social.

Ao optarem por uma determinada linha de orientação - e, principalmente, ao definirem o contingente de jovens atendidos, os objetivos perseguidos, as estratégias a serem aplicadas, o papel reservado ao jovem e as soluções buscadas - , os programas de políticas públicas circunscrevem discursos sobre juventude, que definem, também, circunstâncias juvenis e modos de viver dos jovens.

Sposito et al. (2006) destacaram a implicação existente entre as políticas públicas e a sociedade como um todo. Segundo os autores, os programas sofrem efeitos das concepções de juventude elaboradas pela sociedade, da mesma forma que esses mesmos programas provocam efeitos nas imagens que a sociedade constrói desses jovens. Entendemos, ainda, que os efeitos não se limitam às concepções sobre juventude. Nesta rede de efeitos, em que estão inseridas as políticas públicas e a sociedade, se constroem modos de ser jovem e modos de relação com os jovens. Sendo assim, as ações de políticas públicas de juventude podem tanto contribuir para criar novos sentidos e práticas para e pelos jovens como podem, simplesmente, reforçar as concepções e modos de viver dominantes reservadas à juventude dita em maior vulnerabilidade social.

\section{Juventude, educação e trabalho}

Dentre as dificuldades enfrentadas pelos jovens, o acesso a postos de trabalho é apontado como particularmente crítico, sendo o índice de desemprego entre eles muito superior ao índice entre adultos. A defasagem existente entre as condições educativas, expectativas de realização e expectativas de inserção no mercado de trabalho explicitam algumas das dificuldades enfrentadas pela maioria dos jovens (UNESCO, 2004). Esses dados evidenciam um forte imbricamento de temas como juventude, educação e trabalho.

O processo de formação profissional não se restringe ao período de capacitação, técnica ou acadêmica. Dito de outro modo, o processo de formação profissional não tem data determinada para começar ou terminar. Muitos são os fatores que incidem nesse processo. Dentre esses fatores, destacamos dois (UNESCO, 2004) que evidenciam a condição dita fragilizada da maioria dos jovens e que, por assim dizer, autorizam a preocupação em se implementar programas de políticas públicas voltados para a educação profissional da juventude. $\mathrm{O}$ primeiro desses fatores de influência no processo de formação profissional é a constante defasagem entre as exigências demandadas pelo mercado formal de trabalho e a capacidade da sociedade de instrumentalizar os jovens com o conhecimento, as habilidades e as atitudes necessárias para se tornarem aptos para responder a essas demandas. O segundo fator, agravante para as condições de trabalho da juventude, é o menor grau de articulação institucional e política dos jovens, se comparado ao grau de articulação dos adultos.

Considerando-se, ainda, a formação profissional dos jovens, a importância da aquisição de habilidades com tecnologias da informação (TIs) tem sido largamente difundida e reconhecida como fator que amplia as chances de inserção no mercado de trabalho. Assim, já se tornou lugar comum afirmar que as TIs proporcionam inovação, vantagens e oportunidades aos seus usuários. A utilização desta ferramenta tem sido amplamente estimulada na formação de jovens, através de projetos de inclusão digital. Por outro lado, é importante problematizar os processos de inclusão que se estabelecem quando os jovens interagem com as tecnologias. Conforme observa Maraschin (2004), o mero encontro entre ferramentas tecnológicas e ferramentas educacionais não garante a promoção de inovação. Do mesmo modo, a UNESCO (2004) salienta que o uso indiscriminado das TIs como instrumento educativo sem avaliação prévia e sem critérios para sua aplicação não é justificável. Segundo Maraschin, a inovação se instaura nos modos como esse encontro reorganiza a rede de conversações ou explicações anteriores. Sendo assim, torna-se relevante observar se as estratégias de inclusão digital são capazes de instigar a instauração de diferenças na rede.

\section{Projeto em foco: o Consórcio Social da Juventude}

O Consórcio Social da Juventude (CSJ) foi um projeto criado a partir do Programa Nacional de Estímulo ao Primeiro Emprego para os Jovens (PNPE), desenvolvido pelo Governo Federal, através do Ministério do Trabalho e Emprego. Esse projeto previu a parceria e a articulação da sociedade civil organizada (instituições de ensino, órgãos públicos, empresas, entidades sociais e órgãos de representação dos trabalhadores) para a elaboração e execução das ações do projeto. No Estado do Rio Grande do Sul, o CSJ teve a sua primeira implementação em 2005 e seguiu com uma nova edição em 2006. Recentemente, no fim de 2007, o CSJ foi integrado ao ProJovem, na ação do Governo Federal de unificação dos programas de juventude.

Dentre as justificativas do CSJ, salientamos a fragilidade no atendimento das redes de apoio aos jovens na área de saúde, habitação, educação, orientação legal 
e alimentação (Brasil, 2005). Esse projeto tinha como objetivo geral oferecer apoio e orientação a jovens em situação dita de maior vulnerabilidade social, inclusive no sentido de esses jovens terem mais acesso a outras políticas públicas. Alguns dos objetivos específicos foram: a formação profissional dos jovens; o desenvolvimento da cidadania; o fortalecimento das redes de proteção dos jovens; e o desenvolvimento de estudos e pesquisas referentes à juventude. Destacamos que a inserção dos jovens no mundo do trabalho foi um de seus principais objetivos. Dessa forma, as atividades visavam promover oportunidades de inserção, para os jovens, em atividades produtivas geradoras de renda: emprego; trabalho autônomo; e trabalho associativo ou autogestionário. O CSJ tinha como meta inserir um mínimo de $30 \%$ dos jovens participantes no mercado de trabalho. Uma das proposições do projeto era a de atribuir significado ao universo do trabalho, buscando, assim, provocar nos jovens o exercício de produção de novos sentidos para o trabalho (Brasil, 2005).

Em cada edição do CSJ, o jovem participava de atividades por um período de cinco meses, durante o qual recebia auxílio financeiro para viabilizar sua permanência no mesmo. O projeto ofereceu aos jovens participantes cursos de qualificação básica (inclusão digital; valores humanos, ética e cidadania; educação ambiental, saúde e qualidade de vida; promoção da igualdade racial e equidade de gênero; ações de estímulo e apoio à elevação da escolaridade; empreendedorismo) e cursos de qualificação específica (aprendizado de uma profissão). Essas atividades contabilizavam um total de 400 horas. Também estava previsto que cada jovem realizasse 100 horas de trabalho voluntário (Brasil, 2005).

Para a implementação do projeto, a estrutura organizada do CSJ no Estado do Rio Grande do Sul foi composta por uma Coordenação Executiva, um Conselho Gestor, um Conselho Executivo, um Centro da Juventude, uma Ouvidoria Jovem, a Entidade Âncora, Entidades Executoras e Entidades Transversais. A cada edição, realizava-se nova escolha das entidades sociais que integrariam o CSJ. A estrutura diversificada e descentralizadora do projeto permitiu que o planejamento, a gestão e a execução das ações ficassem sob a responsabilidade de organizações locais, mesmo que seguissem diretrizes básicas previamente definidas por órgãos federais. Assim, todas as atividades referentes à realização do projeto foram planejadas, geridas e executadas por várias entidades pertencentes a diferentes categorias e localidades das cidades participantes. $\mathrm{Na}$ edição de 2006, na região metropolitana de Porto Alegre, o CSJ atendeu a um total de 1.992 jovens, sendo que 315 não completaram as atividades previstas e, por isso, foram considerados como evadidos.

\section{Caminhos investigativos}

Segundo Foucault (1969/1997), precisamos nos inquietar diante de determinados recortes ou grupamentos que, para nós, se tornaram muito familiares. $\mathrm{O}$ autor ressalta que a distinção entre esses grupamentos é inexistente, uma vez que eles mantêm relações complexas entre si. Esses recortes e grupamentos, que identificamos como tais, são "categorias reflexivas, princípios de classificação, regras normativas, tipos institucionalizados: são por sua vez fatos de discurso que merecem ser analisados ao lado dos outros" com os quais mantêm intensa relação (Foucault, 1969/1997, p. 25).

Instigados por essa inquietação proposta por Foucault, focamos o eixo de análise nas políticas públicas de juventude. Nossa questão inicial foi procurar entender que efeitos de verdade têm os discursos de políticas públicas que possam delinear determinadas concepções de ser jovem. Tivemos como estratégia definir o sistema de prescrição para os jovens inseridos em uma política pública, as suas formas de sucessão, de simultaneidade, de repetição, de institucionalização, enquanto objeto do discurso.

Foucault também observa a fragilidade da autonomia da unidade discursiva, tomando como exemplo o livro. A obra não se origina ou se encerra em si mesma, ela está sempre ancorada em uma rede discursiva, estando atrelada a outras obras, outros livros e textos. Contudo, "mesmo entendida como feixe de relações, [a unidade] não pode ser considerada como idêntica" (Foucault, 1969/1997, p. 26). Da mesma forma, consideramos que documentos de políticas públicas, mesmo que sejam unidades materiais, se constroem a partir de uma rede complexa de discursos e, assim, são unidades variáveis e relativas. Ao analisarmos os documentos de que dispomos, sejam manuais, avaliações ou entrevistas, devemos entendê-los como efeitos e deflagradores de efeitos dentro de uma rede discursiva. Procuramos analisar o discurso não como uma unidade fechada, mas enquanto multiplicidade de enunciados possíveis em um campo de coexistências.

Para a realização dos objetivos desta pesquisa, escolhemos um determinado projeto de política de juventude lançado pelo Governo Federal, o Consórcio Social da Juventude (CSJ), cujas características foram descritas no item anterior. Além de sua orientação descentralizadora e especificidade no foco juventude, abrangendo questões pertinentes ao trabalho e à educação juvenil, outras circunstâncias nortearam a nossa escolha: o fato de o projeto estar ativo no período do estudo - o que facilitaria possíveis novos contatos com as pessoas envolvidas - , além de sua abrangência nacional e a importância social relacionada ao mesmo. 
Focamos a nossa investigação na experiência da cidade de Porto Alegre, RS. Inicialmente, fizemos contato com a entidade Âncora, entidade responsável pela coordenação do CSJ. A partir desse contato, recebemos a sugestão de nomes de algumas entidades - executoras e transversais - que integraram o projeto e com as quais poderíamos estabelecer diálogos. Realizamos entrevistas com dez agentes dessas entidades, dentre eles gestores, executores e coordenadores. A seleção dos documentos foi feita, principalmente, através desses contatos. Dentre esses documentos estavam projetos de proposições de participação no CSJ, planos de trabalho, avaliações parciais e de conclusão das atividades. Tivemos acesso aos documentos de âmbito nacional através da Internet.

A utilização de documentos que não estavam ligados diretamente ao CSJ, como o Plano Nacional de Juventude (Brasil, 2004), justificou-se, principalmente, em função da discussão desenvolvida anteriormente. Ou seja, é necessário que façamos a análise levando em consideração a multiplicidade do discurso, o seu campo de coexistências e a importância de justapormos diferentes enunciados, destacando as concepções de juventude que se estabelecem no conjunto dos documentos e entrevistas. Relativamente às discussões desenvolvidas neste artigo, tomamos como indicadores de análise os imbricamentos entre juventudes e o trabalho voluntário, as tecnologias da informação, o trabalho formal e a vulnerabilidade social. Pensamos que, por meio desta análise, foi possível pôr em questão como essa singularidade - o jovem do CSJ — pôde falar de relações e de processos mais coletivos que destacam o modo como, na contemporaneidade, se constroem determinadas juventudes das camadas de baixa renda.

\section{O jovem que emerge do projeto}

Ao analisarmos os documentos elaborados para e pelo CSJ, constatamos fases distintas em que se observam diferentes processos de elaboração de discursos sobre juventude. Essas fases vão desde a descrição das diretrizes do programa até a confecção dos relatórios parciais e de conclusão das atividades. Nos documentos é definido o público-alvo do projeto (jovens em situação de maior vulnerabilidade social) e é estabelecido o que é preciso oferecer aos jovens assistidos e, também, o que se espera desses e para esses jovens. Essas caracterizações, prescrições e expectativas revelam modos de como as políticas têm constituído um discurso sobre o que é ser jovem e o que se espera desse jovem.

Foi possível, assim, visibilizar quatro concepções de juventudes delineadas nos enunciados analisados.
São elas: juventude voluntária, juventude digitalizada, juventude trabalhadora e juventude vulnerabilizada. Essas categorias se constituíram em quatro indicadores de análise que, ao serem interpretados à luz do aporte teórico escolhido, se mostraram importantes para as problematizações desenvolvidas.

\section{Juventude voluntária}

$\mathrm{Na}$ análise dos documentos referentes ao CSJ, identificamos um estreito vínculo entre a realização do serviço voluntário e o recebimento do auxílio financeiro. Em diferentes trechos do documento Manual de Implementação Junto às Entidades Sociais (Brasil, 2005), consta que a realização do trabalho voluntário é condição para que o jovem tenha direito ao recebimento do auxílio financeiro. Uma vez que o trabalho é obrigatório para o pagamento do auxílio, a utilização do termo "voluntário" pode causar estranheza na situação do CSJ. Estranheza que é perceptível nas entrevistas com alguns profissionais, que optaram pelo uso de expressões como "ação social" ou "serviço comunitário" no lugar de "trabalho voluntário". No Relatório de Avaliação do II Módulo do CSJ-RS (Escola Técnica José de Alencar Mesquita, 2006), observamos que o item 3.2 tem como título "Trabalho Voluntário/Comunitário". Essa duplicidade de designações pode ser entendida como outro indício da ambiguidade dessa prática no CSJ. Mais detalhadamente, no corpo desse mesmo item, os autores usaram o termo "Trabalho Comunitário" para tratar do trabalho exercido como exigência do CSJ. Contudo, quando o objetivo foi destacar que a maioria dos jovens continuou exercendo esse trabalho após o cumprimento das horas obrigatórias, os autores utilizaram o termo "Voluntariado".

Ao analisarmos os enunciados que constituem estas práticas, não podemos deixar de relacioná-los com outros enunciados presentes em outras propostas de políticas de juventude. O Plano Nacional de Juventude, por exemplo, opera com o conceito de cidadania, afirmando-a através de práticas que podem ser inscritas na lógica do trabalho voluntário. Contudo, nesse contexto, as práticas voluntárias estão marcadas por funções tais como: solidarizar-se, desprender-se de si, doar-se. Nesse sentido, observamos que os projetos sociais educativos, inseridos em políticas públicas e coordenados pelo poder público, precisam se diferenciar dos programas assistenciais, frequentemente desenvolvidos por outros setores da sociedade, como as ações comunitárias de congregações religiosas.

O trabalho voluntário tem se afirmado em diversos âmbitos, constituindo-se como referência para afirmação da cidadania; e, ao ganhar visibilidade nos setores públicos e privados, pode inscrever-se como matriz 
das relações de trabalho, de assistência, de educação e de avaliação de projetos sociais. Destacamos aqui algumas considerações feitas por Lobo (2003) acerca do direcionamento dado a algumas práticas promotoras de trabalho voluntário decorrentes de políticas públicas. A autora aponta para os riscos destas práticas em contextos em que o Estado desobriga-se cada vez mais da manutenção e coordenação de serviços básicos de educação e saúde:

"2001 - Ano Internacional do Trabalho Voluntário" - estratégia global de desvitalização das lutas sociais e de controle das populações do terceiro mundo. Neste contexto, o trabalho voluntário não passa de um eufemismo atual para as práticas de tutela semelhantes ao higienismo e à filantropia, resquícios de um passado ainda presente, esvaziamento do sentido político da solidariedade, cujo efeito mais deletério é o conformismo. (pp. 312-313)

Por outro lado, quando as ações voluntárias inscrevem-se num conjunto de práticas que vão além do discurso da servidão ou da precarização, outros desdobramentos são possíveis - o que pôde ser apontado em experiências do CSJ, nas quais o trabalho comunitário assumiu outros sentidos. Em alguns casos, ele adquiriu caráter de estágio (Escola Técnica José de Alencar Mesquita, 2006), quando o jovem pôde exercitar atividades na qual buscava qualificação. Outro encaminhamento informado pelos gestores foi o de que alguns jovens foram contratados, ao fim do projeto, pela instituição na qual realizaram o trabalho comunitário. Alguns relatos destacaram que vários jovens, que a princípio tinham resistência quanto às ações comunitárias, optaram por dar seguimento ao trabalho mesmo após o término do projeto.

O tema trabalho voluntário é um riquíssimo analisador, especialmente pelos diversos efeitos e relações que suscita. Observamos que ele permitiria investigações mais aprofundadas, que ampliariam em muito o foco do presente estudo - desdobramentos que pretendemos desenvolver em um futuro artigo.

\section{Juventude digitalizada}

A análise do Manual de implementação junto às entidades sociais (Brasil, 2005) possibilitou compreender que os discursos que sustentam a inclusão digital em projetos de políticas públicas de juventude estão ancorados, entre outros, nos discursos de qualificação e de mercado de trabalho - o que refletiria algumas impressões iniciais deste artigo. Adicionalmente, discursos de educação e de cidadania, que engendram o rendimento escolar, a autonomia, a acessibilidade e a troca de informação, também puderam ser observados no Plano Nacional de Juventude (Brasil, 2004).
Mesmo que a inclusão digital faça parte das premissas de programas de políticas públicas, observamos que a discussão sobre sua prática mostrou-se exígua no conjunto do material analisado. Em apenas um dos documentos acessados encontramos alguma reflexão sobre as atividades vinculadas à inclusão digital desenvolvida. Neste documento, Relatório de Avaliação do II Módulo do CSJ-RS (Escola Técnica José de Alencar Mesquita, 2006), foi destacada a importância da transversalidade para o trabalho em focos específicos como a informática e foi sugerido o aumento da carga horária e do aprofundamento do curso de inclusão digital. Contudo, essas sugestões não foram justificadas e nem melhor explicadas. Nos demais documentos, as referências feitas ao curso de inclusão digital se limitavam, em geral, a informar quem seria responsável pelas atividades. Por outro lado, os gestores de uma das entidades responsáveis por esse curso, ao analisarem a sua experiência no CSJ, entenderam que alguns jovens produziram novos sentidos: na percepção de si, na relação com o outro, na valorização de experiências pessoais e dos colegas. Dessa forma, apontamos que seria importante aprofundar a problematização dos modos como os jovens se apropriaram do conhecimento produzido, investigando se e como eles seguiram com o uso de novas estratégias de ação - desdobramentos que ultrapassam os objetivos do presente artigo.

Baseados nos documentos e nas entrevistas com os gestores, apontamos que a rede social formada pelas entidades do projeto não parece ter sido capaz de implicar de forma significativa as atividades desenvolvidas no curso de inclusão digital com as atividades desenvolvidas nos cursos de qualificação básica e qualificação específica, apesar de esforços isolados. Somando-se esse direcionamento à exiguidade da discussão desenvolvida nos documentos, se expressam indícios de invisibilidade quanto à inclusão digital dos jovens beneficiários das políticas. Perguntamo-nos quais os imbricamentos dessa invisibilidade. Podemos apontar a inscrição de uma certa banalidade com relação ao que seja inclusão digital, uma vez que a análise dos documentos aponta para uma mera introdução de ferramentas de TIs sem destaque para a promoção de inovações - risco observado no item "Juventude, educação e trabalho". Alguns entrevistados comentaram que os jovens já faziam uso frequente de aparatos digitais, tais como câmeras, celulares e computadores - dado que, segundo uma entrevistada, não foi contemplado pelo projeto. A análise apontou para a importância de se rever os discursos que amparam os conceitos de inclusão e de exclusão digital. Partindo-se do entendimento de inclusão digital perceptível no projeto - como mero uso de ferramentas de TIs - , esses jovens já estariam incluídos digitalmente. Os jovens do 
CSJ, em maior ou menor grau, também estão inseridos na rede de consumo de aparatos midiáticos. Importa, então, desenvolver juntamente com os jovens modos mais criativos, instauradores de diferença, para o uso das tecnologias. De qualquer modo, o discurso de inclusão digital parece, de forma limitada, servir mais como uma das muitas justificativas que emprestam legitimidade à elaboração de políticas públicas de juventude.

\section{Juventude trabalhadora}

Conforme apontamos na discussão teórica, tem se dado maior visibilidade às implicações entre trabalho e juventude, o que foi perceptível no projeto investigado. Todo o processo de formação do CSJ visava propiciar aos jovens alternativas de geração de renda - fato determinante para o perfil do jovem participante, uma vez que, segundo um dos gestores, buscavam-se jovens que tivessem a intenção de se engajar em um trabalho formal.

Adicionalmente, uma das exigências do CSJ era que toda entidade executora alcançasse a meta de pelo menos $30 \%$ de jovens vinculados a atividades formais e comprovadas de geração de renda ao fim do projeto. Caso a entidade não alcançasse a meta, era obrigada a devolver parte da verba recebida para o projeto, segundo um dos gestores. Esse contexto configurou uma das principais tensões do projeto. Alguns jovens que haviam passado por uma determinada formação profissional, como telemarketing, foram empregados para funções que não correspondiam a essa formação, como serviços gerais. Dessa forma, verificamos que vários discursos que justificam a realização de projetos de políticas de juventude, como os discursos de educação, cidadania, superação, produção de novos sentidos, ficaram subjugados a outros discursos, por exemplo, do mercado de trabalho. Esse foi um grande nó do projeto, claramente reconhecido pelos gestores e executores das entidades. Ou seja, o CSJ, que tinha como objetivo proporcionar aos jovens estratégias de produção de novos sentidos para o trabalho, ao fim, também repetiu alguns modelos usuais de emprego para jovens de baixa renda. Porém, devemos ressaltar que nem todos os casos foram assim. As entrevistas propiciaram relatos de experiências em que os jovens puderam desenvolver novas formas de trabalhar, com satisfação pessoal, criatividade, autogestão e autonomia.

A análise do Plano Nacional de Juventude (Brasil, 2004) permitiu-nos outras considerações. Ficou perceptível, nesse documento, a relação existente entre o conjunto de justificativas para se incrementar as oportunidades de trabalho de jovens de baixa renda com o discurso de marginalização - que é frequentemente endereçado à juventude pobre e/ou de periferias.
Identificamos, ainda, a implicação entre a falta de ocupação e o subemprego com um provável destino de delinquência desses jovens - como se, por não ter alguma ocupação formal (participação em projetos ou trabalho), esse determinado jovem se tornaria um adulto marginal. Para ilustrar, extraímos o seguinte trecho do

\section{Plano Nacional de Juventude:}

As causas do desemprego juvenil são várias, tendo como principal a recessão econômica que castiga o País há mais de duas décadas. Todavia o Poder Público não pode esperar pela recuperação econômica para resolver o problema do desemprego juvenil, visto que a falta de ocupação e o subemprego, muitas vezes, resulta na marginalidade que encoraja a delinqüência nas periferias das metrópoles brasileiras. (p. 11)

Os enunciados dos documentos apontam que as políticas públicas compreendem as dificuldades encontradas por todos para se inserirem no mercado de trabalho. Entretanto, são elaborados projetos com prazos curtos e ferramentas limitadas. Seria importante desenvolver programas mais coerentes com o contexto vivido e que vislumbrassem metas mais plausíveis. Uma vez mais, o discurso econômico é privilegiado. De forma generalizada, resta aos discursos de educação, superação, cidadania, inclusão, entre outros, o papel de servirem de justificativa aos programas de políticas públicas.

\section{Juventude vulnerabilizada}

Outro indicador de nossa análise foi o discurso de vulnerabilidade social que caracterizaria parcelas da população jovem. Nos vários documentos analisados, onde são apresentadas as diretrizes do CSJ - enquanto projeto de política pública para juventude - ou onde são desenvolvidas avaliações e acompanhamentos das atividades, verificamos, nos trechos que fazem referência ao público-alvo das iniciativas, expressões como: jovens "em situação de maior vulnerabilidade social" (Brasil, 2005; Escola Técnica José de Alencar Mesquita, 2006); "em situação de vulnerabilidade pessoal e risco social", "com vulnerabilidade econômica, pessoal e social" e "em vulnerabilização" (Escola Técnica José de Alencar Mesquita, 2006); "em situação de vulnerabilidade social" (Associação Beneficente Amurt-Amurtel, 2006). Encontramos essa terminologia, também com frequência, em artigos (Castro \& Abramovay, 2002, 2004; Sposito \& Carrano, 2003; Sposito \& Corrochano, 2005; Sposito et al., 2006) que tratam do tema das políticas públicas voltadas para jovens.

No processo de análise do material de pesquisa, ficamos intrigados com a utilização dessas expressões. Indagamo-nos a que o termo vulnerabilidade social se refere. Entendemos que, quando este termo é usado, 
nos documentos e artigos, ele traduz a tentativa de se definir uma parcela da população jovem - foco dos programas e projetos de políticas públicas para juventude - que está mais exposta a dificuldades várias, como econômicas, sociais, educacionais e de trabalho. Porém, ao consultarmos a palavra vulnerabilidade no dicionário (Ferreira, 1999) verificamos que ela faz referência à condição de se estar vulnerável a algo, em função de se apresentar pontos fracos, e, assim, o sujeito se encontraria numa situação propícia a acontecimentos indesejáveis. É importante observar que esse é o ponto de vista do avaliador, o que necessariamente não precisa coincidir com a opinião do sujeito que supostamente se encontra nessa posição. Portanto, mais do que definir um estado presente e indesejado - como miséria, discriminação, exclusão, desemprego, falta de acesso à educação e saúde -, o estado de vulnerabilização faz alusão a um determinado futuro, que é aceito praticamente como certo. Esse provável futuro é temido e se pressupõe que irá, indubitavelmente, acontecer, a não ser que se tomem medidas eficazes. Isso porque, de forma geral, a sociedade compreende que esse futuro implicaria situações de risco para a ordem vigente, ou seja: a transformação desse jovem num desempregado, drogado, ladrão, agressor, transgressor da lei. Dessa forma, essa posição subjetivada de vulnerabilizados socialmente, ao invés de destacar as demandas dos jovens e a potencialidade de transformação das condições atuais indesejadas por esses jovens - inclusive com a participação deles -, lhes é conferida uma virtualidade de causadores de problemas sociais. Assim, o futuro temido passa a ser o presente incontestável desses jovens. $\mathrm{E}$ de acordo com esse futuro-presente são elaborados projetos de políticas públicas de juventude.

Destacamos que a tendência apontada acima contrasta com alguns encaminhamentos perceptíveis em trechos dos documentos do CSJ-RS e nos relatos dos gestores. Esses dados apontam que o CSJ também buscou expressar diferentes extratos da juventude e seus modos de viver. Contudo, salientamos que, apesar das tentativas de superação do discurso da precarização, o ponto de partida era sempre o econômico, uma vez que a definição dos jovens aceitos no projeto priorizava o corte de renda - conforme observado por um dos gestores.

\section{Considerações finais}

Para esta pesquisa, tivemos acesso a uma grande quantidade de dados, incluindo dois documentos de âmbito federal e um amplo conjunto de documentos e relatos referentes a experiências de algumas entidades na cidade de Porto Alegre-RS. Destacamos que, mes- mo que a investigação tenha circunscrito um recorte das políticas públicas, as práticas exercidas neste conjunto não estão isoladas da rede que compõem. Os indicadores de análise utilizados (as quatro concepções de juventude visibilizadas) mostraram-se profícuos em apontar nós de tensão existentes no projeto investigado. Assim, as reflexões desenvolvidas contribuíram para um maior entendimento de como o público-alvo dos programas - de forma generalizada, jovens de baixa renda - são tomados como foco e problema de políticas públicas.

As quatro concepções de juventude visibilizadas (voluntária, digitalizada, trabalhadora e vulnerabilizada), esboçadas a partir da análise dos dados, constituíramse em indicadores importantes para a problematização proposta. A análise das práticas discursivas produzidas ou articuladas pelos relatos e documentos investigados apontou que as políticas públicas delineiam expectativas e modos de vida que seriam específicos dos jovens participantes - delineamento que define esses jovens como mais passíveis de ser origem e causa de problemas sociais. A análise das concepções de juventude digitalizada e juventude trabalhadora possibilitou, em especial, destacar a invisibilidade conferida aos jovens de baixa renda. Seja quando as práticas dos projetos resultam em processos limitados de inclusão digital ou quando implicam a contratação dos jovens em funções que se mostram incapazes de contribuir para a produção de novos sentidos. A concepção de juventude vulnerabilizada parece ser restrita ao conjunto de jovens que é objeto das políticas. Assim, o emblema de vulnerabilização conferido a esses jovens pode intensificar o processo de exclusão e, também, despotencializar o campo de ação dos mesmos. Adicionalmente, quando problematizamos a concepção de juventude voluntária, destacamos a ambiguidade identitária conferida aos jovens em foco, uma vez que recaem sobre esse jovem, dito vulnerabilizado, as expectativas de superação - pessoal e social. Acrescentamos que os enunciados de vulnerabilidade permitem compreender que quem está vulnerável não são somente ou necessariamente os jovens, mas, especialmente, as parcelas da sociedade que se sentem em risco em função do futuro virtual de marginalização, em geral, conferido à juventude foco das políticas. Contudo, apontamos que o CSJ desenvolveu algumas estratégias que consideraram os jovens em sua diversidade, havendo inclusive indícios de produção de novos sentidos e modos alternativos de ser jovem.

As análises feitas aqui certamente não esgotam os pontos possíveis de discussão. Elas apontam direcionamentos para futuras investigações que, de forma significativa, contribuiriam para o aprofundamento do entendimento da relação entre políticas públicas 
e juventude. Talvez uma grande aprendizagem desse percurso, e que já havia sido destacada por Sposito e Carrano (2003), seja a necessidade de se considerar a juventude em seu plural. Além disso, esse estudo aponta para a importância de serem desenvolvidos mecanismos e estratégias participativas dos próprios jovens no planejamento, execução e análise dos programas. Como observou Abad (2002), as demandas ditas de juventude são especificadas por determinados setores da sociedade. $\mathrm{O}$ autor questiona quem são esses setores e quais setores podem se mobilizar em favor da juventude. Até porque esses grupos são, em sua maioria, integrados por adultos que nem sempre são sensíveis aos pontos de vista dos jovens - o que implica a forte presença da ótica adulta na elaboração dos projetos. Por fim, destacamos que é no campo da ação que os documentos se transformam em práticas, abrindo novas possibilidades. Nesse campo fértil de enunciados diversos podem emergir atitudes e propostas diferenciadas. Tal foco deve ser valorizado em estudos futuros.

\section{Nota}

1 O Fome Zero é um programa criado pelo presidente Luis Inácio Lula da Silva em 2003. Por meio da articulação com diversos ministérios, "o governo federal articula políticas sociais com estados e municípios e, com a participação da sociedade, implementa programas e ações que buscam superar a pobreza e, consequentemente, as desigualdades de acesso aos alimentos em quantidade e qualidade suficientes, de forma digna, regular e sustentável". Acesso em 24 de julho de 2008, em: http://www.fomezero.gov.br/o-que-e

\section{Referências bibliográficas}

Abad, M. (2002). Las politicas de juventud desde la perspectiva de la relacion entre convivencia, ciudadania y nueva condicion juvenil. Ultima década, 10(16), 117-152.

Associação Beneficente Amurt-Amurtel. (2006). Projeto consórcio da juventude. Porto Alegre: Autor.

Brasil. (2004). Projeto de Lei n. 4530. Plano Nacional de Juventude. Acesso em 29 de abril, 2008, em http://www2.camara. gov.br/internet/eve/realizados/juventude/projetolei.pdf

Brasil. Ministério do Trabalho e do Emprego. (2005). Manual de implementação junto às entidades sociais. Acesso em $10 \mathrm{de}$ setembro, 2006, em http://www.mte.gov.br/pnpe/manual.pdf

Castro, M. G. \& Abramovay, M. (2002). Por um novo paradigma de se fazer políticas. Revista Brasileira de Estudos de População, 19(2), 19-46.

Castro, M. G. \& Abramovay, M. (2005). Juventudes no Brasil vulnerabilidades negativas e positivas, desafiando enfoques de políticas públicas. In J. C. Petrini \& V. R. S. Cavalcanti (Orgs.), Família, Sociedade e Subjetividades (pp. 54-83). Petrópolis: Vozes.

Centro de Assessoria Multiprofissional (CAMP). (2006a). Projeto consórcio da juventude. Porto Alegre: Autor.

Centro de Assessoria Multiprofissional (CAMP). (2006b). Projeto pedagógico. Porto Alegre: Autor.
Centro de Assessoria Multiprofissional (CAMP). (2006c). Relatório de execução. Porto Alegre: Autor.

Escola Técnica José de Alencar Mesquita. (2006). Relatório de avaliação do II módulo do CSJ-RS. Porto Alegre: Autor.

Ferreira, A. B. de H. (1999). Novo Aurélio Século XXI: o dicionário da língua portuguesa ( $3^{\mathrm{a}} \mathrm{ed}$. rev. e ampl.). Rio de Janeiro: Nova Fronteira.

Ferretti, C. J., Zibas, D. M., \& Tartuce, G. L. B. P. (2004). Protagonismo juvenil na literatura especializada na reforma do ensino médio. Cadernos de Pesquisa, 34(122), 411-423.

Foucault, M. (1984). O cuidado com a verdade. In C. H. Escobar (Org.), Michel Foucault (1926-1984). O Dossier: últimas entrevistas (pp. 74-85). Rio de Janeiro: Livraria Taurus Editora. (Original publicado em 1984)

Foucault, M. (1995). O sujeito e o poder. In H. Dreyfus \& P. Rabinow (Eds.), Michel Foucault, uma trajetória filosófica: para além do estruturalismo e da hermenêutica (pp. 231-249). Rio de Janeiro: Forense Universitária. (Original publicado em 1982)

Foucault, M. (1997). A arqueologia do saber. Rio de Janeiro: Forense Universitária. (Original publicado em 1969)

Foucault, M. (1999). A ordem do discurso. São Paulo: Edições Loyola. (Original publicado em 1971)

Lima, S. M. \& Minayo-Gomez, C. (2003). Modos de subjetivação na condição aprendiz: embates atuais. História, Ciência e Saúde, 10(3), 931-953.

Lobo, L. F. (2003). Higienismo e normalização da infância no Brasil. In A. M. Jacó-Vilela, A. C. Cerezzo, \& H. B. C. Rodrigues (Orgs.), Clio-Psyché paradigmas: historiografia, psicologia, subjetividades (pp. 291-320). Rio de Janeiro: Relume Dumará/FAPERJ.

Maraschin, C. (2004). Pesquisar e intervir. Psicologia e Sociedade, 16(1), 98-107.

Organização das Nações Unidas para a Educação, a Ciência e a Cultura (UNESCO). (2004). Políticas públicas de / para / com Juventudes. Brasília: UNESCO.

Sposito, M. P. \& Carrano, P. C. R. (2003, setembro/dezembro). Juventude e políticas públicas no Brasil. Revista Brasileira de Educação, 24, 16-39.

Sposito, M. P. \& Corrochano, M. C. (2005). A face oculta da transferência de renda para jovens no Brasil. Tempo SocialRevista de Sociologia da USP, 7(2), 141-172.

Sposito, M. P., Silva, H. H. C., \& Souza, N. A. (2006). Juventude e poder local: um balanço de iniciativas públicas voltadas para jovens em municípios de regiões metropolitanas. Revista Brasileira de Educação, 11(32), 238-257.

Tommasi, L. (2004, janeiro/abril). Um olhar sobre as experiências de políticas públicas de juventude na América Latina. Revista Brasileira de Educação, 25, 177-181.

Zibas, D. M., Ferretti, C. J., \& Tartuce, G. L. B. P. (2006). Micropolítica escolar e estratégias para o desenvolvimento do protagonismo juvenil. Cadernos de Pesquisa, 36(127), 51-85.

Marcia Frezza é graduada em Psicologia pela UFRJ e Mestre em Psicologia Social e Institucional pela UFRGS. Atualmente é professora auxiliar N2 do Curso de Psicologia da Universidade de Fortaleza (UNIFOR). Endereço para correspondência: Universidade de Fortaleza - Av. Washington Soares, 1321, bloco P, sala 17, Fortaleza/CE. CEP 60811-905. E-mail: marciafrezza@unifor.br frezzamarcia@yahoo.com.br 
Cleci Maraschin é graduada em Psicologia pela UFRGS, Mestre e Doutora em Educação pela UFRGS. Atualmente é professora associada da UFRGS e diretora do Instituto de Psicologia/UFRGS desde 2006. Endereço para correspondência: Universidade Federal do Rio Grande do Sul - Rua Ramiro Barcelos, 2600. Santana, Porto Alegre/ RS. CEP 90035-003. E-mail: clecimar@orion.ufrgs.br

Nair Silveira dos Santos é graduada em Psicologia pela Universidade do Vale do Rio dos Sinos, Mestre e Doutora em Educação pela UFRGS. Atualmente é professora adjunta do Instituto de Psicologia da UFRGS. Endereço para correspondência: Universidade Federal do Rio Grande do Sul - Rua Ramiro Barcelos, 2600, sala 13A. Santana, Porto Alegre/RS, CEP 90035-003. E-mail: niss@terra.com.br

\section{Juventude como problema de políticas públicas}

Marcia Frezza, Cleci Maraschin e Nair Silveira dos Santos

Recebido em: 16/06/2008

Revisão em: 01/08/2008

Aceite final em: 08/08/2008 